\title{
Towards the Customers' Intention to Use QR Codes in Mobile Payments
}

\author{
Victor Chang, Teesside University, Middlesbrough, UK \\ Waner Chen, Imperial College, London, UK \\ Qianwen Xu, Teesside University, Middlesbrough, UK \\ Chang Xiong, Xi'an Jiaotong-Liverpool University, Suzhou, China
}

\begin{abstract}
This research studies the motivation of customers to choose the QR code as a payment tool by developing an integrated model based on UTAUT. Four hundred twenty-four valid responses were collected from diversified socio-economic backgrounds to validate the proposed framework. Compared with the original UTAUT model, the new one integrates 'perceived security', 'perceived benefits', and excludes 'social influence' to provide more comprehensive and consistent guidance. PLS-SEM technique was performed as in the data analysis process using SmartPLS. The study concluded that seven of nine hypotheses are supported by the use of PLS-SEM technique. Customers' intention $(\mathrm{R} 2=0.87)$ to use $\mathrm{QR}$ code as the payment tool is jointly contributed by their attitude, perceived usefulness, and subjective norms toward using QR code as the payment method. The formation of customers' attitudes $(\mathrm{R} 2=0.79)$ towards using $\mathrm{QR}$ code is affected by their perceived usefulness, perceived benefits, and subjective norms. Discussion and strategies for the third parties of QR payment providers and future research directions are also presented.
\end{abstract}

\section{KEYWORDS}

Data Analytics, Internet of Things, Mobile Payment, QR Code Payment, Unified Theory of Acceptance and Use of Technology (UTAUT)

\section{INTRODUCTION}

\subsection{Overview}

A smart life is a lifestyle that connects to the internet and allows many services and activities. These include storing and accessing cloud storage computing and other advanced solutions to achieve the free-flow of information, capital and materials regardless of the time and space. Mobile payment, as one of a core approach to this kind of society, is adopted by a range of users, contributing to a more effective and efficient lifestyle. Technology contributes to continuous development for mobile payment because of the establishment of online payment services from the interactions among banks and many third-party payment platforms. The flexible mobile terminals and the well-constructed 5G and Wi-Fi facilities, also contribute to the popularity of mobile payment. Cashless society benefits not only the users for cost-saving but also the service providers for data-collecting.

As a particular kind of mobile payment tool, QR codes are provided in the majority of cashier desks, particularly in China. It can be used easily regardless of the size and the location of these stores. 

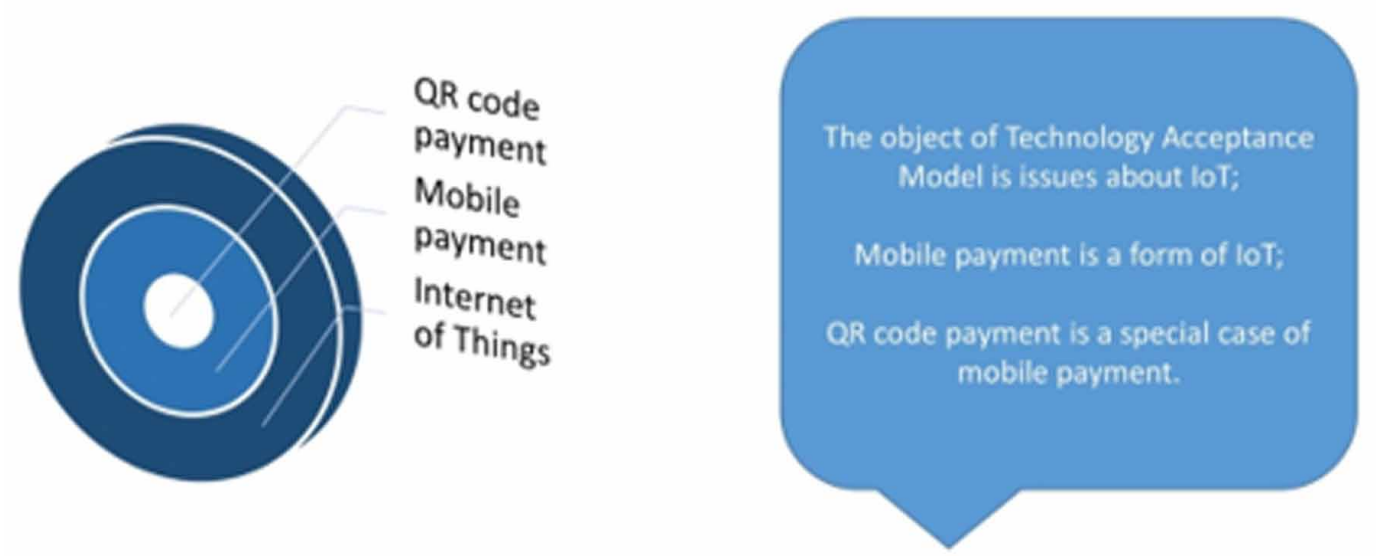

While among the existing literature, lots of research has been conducted on the employment of mobile payment methods, limited research has paid attention to the status of QR code payment, which is one specific type of mobile payment methods. Figure 1 shows an IoT-based mobile-payment system for our research focus. This paper collected data from China because QR code payment has become the most popular and commonly used mobile payment method across the country. The phenomenon of stopping using this method has appeared. Therefore, it is essential to scrutinize how to maximize the diffusion of QR codes and what factors influence customer behaviors to accept this payment method. In order to enhance our understanding of the adoption of new payment methods, the current study aims to answer: What are the antecedents of customers' motivation in using a new payment method?

\subsection{Mobile Payment System}

The service used financial technology (fintech) is to combine finance and emerging technology altogether, such as Artificial Intelligence, Blockchain, Internet of Things (IoT) and others (Nicoletti, 2017). With the development of the fourth industrial revolution, financial technology has been more and more popular (Tasca et al., 2016). There are many kinds of fintech services, including the mobile payment system. Mobile payment systems are defined as any payment methods in which the business transaction is conducted with the use of a mobile device (Ozturk et al., 2017), and they are supported by emerging technologies, such as the Internet of Things, Near Field Communication (NFC) and smart devices (Lee, 2015). Mobile payment systems take multiple forms, including NFC, Sound waves-based payments, Magnetic secure transmission (MST) payments, Quick response (QR) code payments and so on (Sorensen, 2018). According to the existing studies on mobile payment, mobile payment's fast, convenient, and useful services are the main factors contributing to the wide acceptance of the technology (Singh, Sinha and Liébana-Cabanillas, 2020).

One of the important emerging technology is IoT and the principle is to connect any item to the internet through radio frequency identification (RFID), a global positioning system (GPS), laser scanner and other sensing types of equipment. According to the agreed protocol, a system using IoT can achieve intelligent identification, positioning, tracking, monitoring and management by exchanging information and communicating with different devices and equipment (Lim et al., 2018). IoT can be employed in many areas, such as public health, intelligent transportation, industry production safety, etc. In the area of the mobile payment system, IoT is used to connect customers' bank cards with merchants' POS machines or other collection devices through smart devices such as mobile phones. Users can operate business activities such as transfer and payment through SMS, proximity sensing, etc. 
An IoT structure consists of multiple layers that jointly provide the basis of various applications, including mobile payment. These layers include the perception network, the communication network, and the information processing center. As the core of the IoT structure, the perception network functions as the fundamental part of the IoT industries. Based on the characteristics the perception network shows under different application contexts, the IoT industries could be categorized as the RFID application industry, the mobile payment industry, and the Wireless Sensor Network industry. Mobile payment, as one of the main applications of the IoT technologies (Xu, Huang and Mi, 2020), has fundamentally transformed the way people make business transactions. Although mobile payment has brought tremendous benefits based on the IoT technologies, user adoption and security issues remain significant (Bayer, Gimpel and Rau, 2020). Recently, these challenges are being resolved using latest technologies such as Blockchain technologies (Mazzei et al., 2020; Smahi et al., 2020).

The other important technology that supporting mobile payment is Data Analytics. No matter the transaction itself, or the problems of security and fraud prevention, the mobile payment system is inseparable from the technology of big data (Jocevski, Ghezzi and Arvidsson, 2020). On the one hand, in the field of payment, using big data analytics to implement anti-fraud behavior analysis is one of the commonly used technical means for payment risk prevention and control. The use of big data analytics improves the security of the payment system by detecting theft and other illegal activities, e.g., whether the payment card is used by the owner of the card. On the other hand, with these data from the payment system, merchants are allowed to optimize their products more easily. While taking the shopping activity as an example, the merchant can clearly identify the reason why a user is hesitating to buy a product by analyzing the data generated during the entire process of locking items, adding shopping carts, settlement, payment, etc. In this way, products can be optimized for a targeted purpose. In addition, the success rate of transactions and the user experience can be improved, thereby promoting the business.

With the development of emerging technologies, some non-financial organizations have made progress in the promotion of mobile payment, such as Apple, Samsung and Alipay. Alipay (Zhifubao), one of the biggest online payment service providers in China, established a strategic partnership with over 180 commercial banks, Mastercard, VISA and other systems to improve convenience and enlarge the application scope of mobile payments (Cao and Niu, 2019). Besides, as the primary competitor of Alipay, Wechat pay decided to launch WeChat Smart Life Solutions and Spark Program to offer $\mathrm{O} 2 \mathrm{O}$ tools among nearly 30 industries and aimed to support payment services providers by various subsidies. Compared to the USA, the country with GDP far more than China, the adoption rate of mobile payment there was far less than that in China. An explanation provided by Big-data Research (2016) was that the credit card payment system was so mature in the USA that the citizens were reluctant to change into another payment type. While in China, residents had not formed a stable payment behavior resulting in higher motivation to use new methods in conducting business transactions.

\subsection{QR Code in Mobile Payment}

QR (Quick Respond) code was initially created by a Japanese firm named Denso Wave in 1994 to enhance auto-tracking. But it eventually became a popular tool for the retail industry to lighten the burden of cashiers by encoding the information on prices of goods into these codes (Sang Ryu, 2013). The 2-D matrix barcode was capable of handling all types of data, such as some plain test, SMS (Short Message Service) and URL (Uniform Resource Locator), only with approximately 1/10 the space of a traditional barcode. Some users could easily generate QR code thanks to the software provided by DENSO WAVE or other online free programs incorporated with all kinds of specific functions. Others could read these target codes through handy scanners like mobile phones equipped with a built-in camera and some scanning applications (DENSO WAVE, 2018).

Various functional codes enhance customer engagement with different brands via the sense of high-speed interactions. For instance, consumers could have easier access to advertisements, 
promotions and some other latest information of products or services by a simple scanning, which allows a deeper involvement. To another party, retailers also experience the benefit of labeling advertisements on products by small QR codes, integrating with other media or printed means to minimal cost and reaching an instant communication with their users (Shin, Jung and Chang, 2012).

Apart from advertisements, enterprises might get better understandings in the consumer market with QR code payment. It also encourages more purchases since payment is easy and quick. According to Liébana-Cabanillas, Luna and Montoro-Ríos (2015), several sectors had implemented mobile payments. For example, Barclay (Barclay Pingit QR Code) bank had added new services to its Pingit Wallet. It is critical for retailers to understand which factors could affect customers' willingness to adopt this kind of payment method to change target promotion and marketing strategy.

Since QR code payment first recognized in China in 2016, it has become the most popular mobile payment method among all kinds of mobile payment methods. Alipay and WeChat are two leaders in the QR code payment market. According to China Payment and Clearing Association (PCAC) (2018), the most commonly used QR code payment scenarios for users are supermarkets, accounting for $89.5 \%$, indicating that QR code payment is mainly used to satisfy users' basic consumer demand. However, although the acceptance of QR code payment method has reached a high level in general, according to the data from 2016 to 2018 (PCAC,2016; PCAC, 2017; PCAC, 2018), it can be seen that during 2018, the proportion of non-acceptance increased slightly, from $8.2 \%$ to $10.9 \%$. It indicates that some users have stopped using the QR code payment method. One of the reasons may be the user's consideration of the security problem, as its number has constantly increased from $52.4 \%$ to $67.5 \%$ and then increased to $77.8 \%$ from 2016 to 2018. In addition, some QR payment security events have occurred in China these years. For instance, criminals can use a QR code to implant a virus into a victim's phone and then unknowingly transfer money from payment applications (Gao et al., 2018).

\section{LITERATURE REVIEW AND HYPOTHESES DEVELOPMENT}

\subsection{Unified Theory of Acceptance and Use of Technology (UTAUT)}

Venkatesh and Morris (2003) proposed the Unified Theory of Acceptance and Use of Technology (UTAUT) based on eight Technology Acceptance theories or Behavior Intention theories, including the Theory of Reasoned Action (TRA), the Technology Acceptance Model (TAM), the Motivational Model (MM), the Theory of Planned Behavior (TPB), a model combining TAM and TPB (C-TAMTPB), the model of PC utilization, the Innovation Diffusion Theory (IDT), and the Social Cognitive Theory (SCT). UTAUT is a more comprehensive and complete model and is used to study the process of technology acceptance and the factors that promote or hinder potential adopters from adopting innovation.

In the UTAUT, four constructs are established to be the determinants of behavioral intention. This intention refers to an individual's willingness to engage in a specific action and the four constructs are performance expectancy, effort expectancy, social influence, and facilitating conditions (Venkatesh and Morris, 2003). In this research, the construct 'facilitating conditions' will be excluded as the smart devices, such as smartphones, which support mobile payments have been common in public, the impact of 'facilitating conditions' is assumed insignificant. In addition, the construct 'attitude' will be added to the modified model. Although 'attitude' was not established in the UTAUT, it is considered in many theories and models of technology acceptance (Ahmad, 2014). Furthermore, several studies have proved that 'attitude' is a significant construct in their cases (Ahmad, 2012; Akbar, 2013; Lescevica et al., 2013). Therefore, 'attitude' will be employed in the model and be evaluated its significance in this research.

According to Campbell (1963), the attitude was defined as a sense acquired from the previous memory about an action, a person, or stuff, which could guide future behavior. Hence, attitude becomes a crucial term that contains positive or negative previous experience. For example, a person has to 
decide whether he/she has the intention to take some specific action. In many fundamental theoretical models of UTAUT, such as Theory of Reasoned Action (Fishbein and Ajzen, 1975) and Theory of Planned Behavior (Ajzen, 1985), the attitude was proposed as a positive driver linked to behavior intention. Additionally, this assumed relation was validated by studied of different topics: E-Health system (Holden and Karsh, 2010), Online shopping (Gefen, Karahann and Straub, 2003), Media use (Rauniar et al., 2014) are among the time and location conditions. This study applies past models to the study of QR code payment and identifies this relationship as an assumption:

\section{H1: Attitude positively affects customers' intention to adopt QR code payment.}

Social influence, which is also called subjective norm, refers to an individual's perceived pressure from his or her chosen social referents to perform the behavior (Xiong et al., 2019). The potential user would regard those people's opinions as useful information and consider their suggestions. Usually, they are the friends, relatives and colleagues of this potential user. Yang and Jolly (2009) compared the differences in mobile data service usage in American and Korean users. The results showed that subjective norms are evident in the promotion of users' attitude and intention to adopt this kind of service among American consumers. Mahon, Cowan and McCarthy (2006) illustrated that subjective norms played an important role in the consumer's attitudes and intentions to accept ready meals in Great Britain. Hasbullah et al. (2016) identified that subjective norms for Malaysian youth were a significant driver for their attitude and intention to enact online shopping.

In the mobile-related area, subjective norm also has been validated as one crucial antecedent to customers' attitudes and intention to adopt mobile services. According to Yang et al. (2012), social influence was significant in the pre-adoption and post-adoption stage for mobile payment. However, the degree of importance was varied at the different stages of adoption, which means that subjective norms function not only the user has the intention to take a new action, but it also matters when he/ she decides whether to keep this action as a habit continuously. Thakur (2013) provided evidence that social influence is regarded as an essential factor for Indian citizens to choose mobile payment instead of using cash. Shin (2009) studies subjective norms in the UTAUT model of the acceptance of the mobile wallet. The result showed that the relationships between subjective norms and the final decision were significant. Hence, this study applies previous assumptions to the QR code payment and the hypothesis are as follows:

H2: Subjective norms positively influence customers' attitudes to adopt QR code payment. H3: Subjective norms positively influence customers' intention to adopt QR code payment.

Perceived usefulness, also called performance expectancy, is defined as 'the degree to which a person believes that adopting a new kind of technology would improve their performance' (Rashed, 2001). In the QR payment context, perceived usefulness means payment method allows users to make quick use of mobile applications (Ticket purchase / Use of mobile coupons). It can also improve user experience by properties such as flexibility and fast speed. Perceived usefulness was proved to be one of the main factors contributing to attitude (Liébana-Cabanillas, Luna and Montoro-Ríos (2015), Chen and Huang (2010)). Hence, this study follows previous researches to provide the same hypothesis:

H4: Perceived usefulness positively influences customers' attitudes to adopt QR code payment. H5: Perceived usefulness positively influences customers' intention to adopt QR code payment.

Ease-of-use, which is also called effort expectancy, has three aspects: easy to use, easy to learn, and easy to become skillful (Segars and Grover, 1993). When it comes to QR code payment, it depends on whether the customer feels that it is easy to follow all the steps and is convenient to pay. 
Additionally, interactions between the QR code payment system and the user should be clear and understandable. Previous studies had different results on the significance of ease-of-use. According to Gefen and Straub (2000), previous studies showed no relationship between perceived ease-of-use and attitude. However, Venkatesh (2000) validated the relationship between perceived ease-of-use and attitude and Gefen and Straub (2000) also support that Perceived Ease-of-use contributed to attitude.

Gefen and Straub (2000) explained the gap between Perceived Ease-of-use and Attitude, which was the different characteristics of Perceived Ease-of-use and Perceived Usefulness. They claimed that Perceived Ease-of-use was more abstract and perhaps it was why people's attitudes varied towards the judgment of Perceived Ease-of-use. They provided a solution to propose that Perceived Ease-of-use affects Perceived Usefulness' and that research validated this assumption. The assumption was also proved by much other research (Saadé and Bahli, (2005), Moon and Kim (2001)). This study applies a similar hypothesis for Perceived Ease-of-use of QR code payment:

H6: Perceived ease-of-use positively determines customers' attitudes to adopt QR code payment. H7: Perceived ease-of-use positively contributes to Perceived usefulness.

\subsection{Perceived Security and Perceived Benefits}

In UTAUT, the two constructs of 'Perceived Security' and 'Perceived Benefits' were not considered. Based on this research and existing literature, these two constructs will be added to the model.

According to Kalakota and Whinston (1997), perceived security could be described as 'a threat that creates a circumstance, condition, or event with the potential to cause economic hardship to data or network resources in the form of destruction, disclosures, modification of data, denial of service, and/or fraud, waste and abuse'. Additionally, according to Ashrafi and S (2008), establishing security regulations to increase the monitory and order in the mobile transaction was necessary. Since the interactions of QR code payment are not physical, users are easy to question the safety of this kind of payment tool in many ways. Firstly, some news and reports have released fraud and hacking issues related to the usage of QR code payment, which would lead to a lack of confidence in mobile payment. More seriously, a similar worry would induce a fear that would lead to resistance to usage and finally negatively affect users' intentions. The second reason is that if some decide to adopt QR code payment, users need to authorize third parties to access their personal information and bank accounts. This money transaction usually is not canceled and refunded. Chiemeke et al. (2011) employed 'security' as a factor in their modified UTAUT model to study the adoption of e-commerce in Nigeria and found the factor was significant. Previous studies also have shown that perceived security has a positive influence on the attitude in the mobile payment area (Yang, Liu and $\mathrm{Yu}, 2015$; and Kim et al., 2010). Hence, understanding that QR code payment is one of the mobile payment methods, this study regards perceived security as a crucial antecedent to attitude:

H8: Perceived security positively affects customers' attitudes to adopt QR code payment.

Due to the fierce competition, most QR code payment service providers of the third-party promote their applications in various forms. For example, if the user adopts the WeChat QR payment on weekends, it would be possible for the user to get some cash rewards.

Besides, Kim et al (2010). claimed that perceived benefit could explain why people have the intention to use mobile internet. One noticeable advantage of QR code payment can reduce transaction costs (time and money). By adopting mobile payment, the consumer has a mobile device with a built-in camera that avoids the exchange of cash and can be finished within several seconds. Compared to the traditional cash payment, $\mathrm{QR}$ code offers better interaction experience and quick response. It is not only for the payer but also for the stores which install this kind of charge method. McDougall and Levesque (2000) explained that perceived value (benefit) is a crucial factor for the 


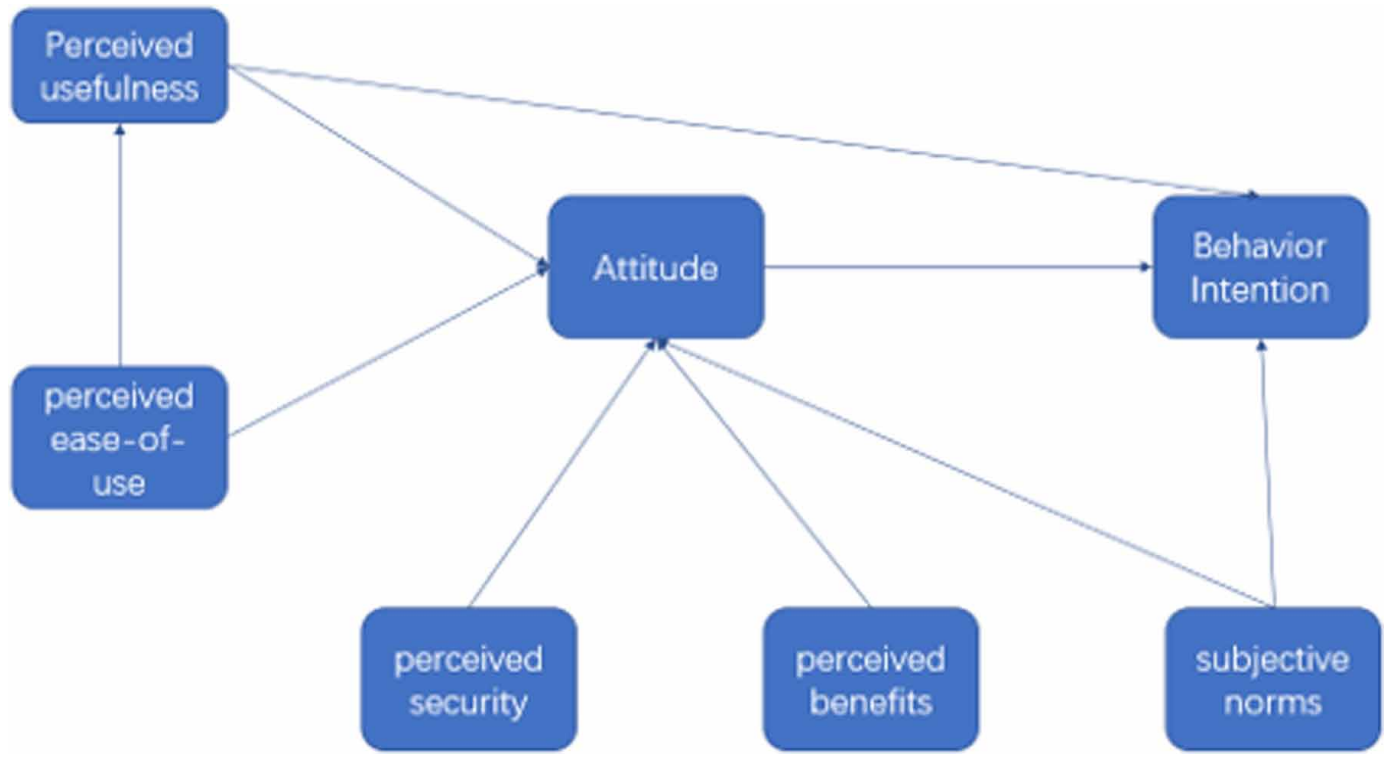

customer satisfaction equation, and satisfaction can positively affect customers' attitudes to products or services. As a result, the higher the level of benefit, the higher the possibility for the customer to adopt and this study states this hypothesis:

H9: Perceived benefits positively determine customers' attitudes to adopt QR code payment.

For better understanding, this study proposes an integrated model based on UTAUT, existing literature and this research to test the significance of certain factors.

The Conceptual model of this study is presented in Figure 2. Attitude, perceived usefulness and subjective norms are assumed to affect customers' intention to enact the behavior directly. Perceived usefulness, perceived ease-of-use, perceived security, perceived benefits and subjective norms are supposed to influence people's attitudes. Compared with the original UTAUT model, the new one integrates 'perceived security', 'perceived benefits' and excludes 'social influence' to provide more comprehensive and consistent guidance. The new framework pays more attention to the QR payment code than the macroscopic of mobile payment. The refined model could also apply to other research targets, which are similar to QR code payments.

\section{METHODOLOGY}

In this section, the methods of data collection and data analysis will be introduced. Firstly, data were collected by administering a questionnaire. The approaches of conducting the survey include using QR codes, weblink and printed questionnaires. After the data collection, the invalid questionnaires were excluded from the sample. Secondly, after the initial data cleaning, exploratory factor analysis was performed to ensure the scale reliability and validity of this study. Then, the hypotheses were tested by employing the Partial Least Squares Structural Equation Modeling technique. Finally, a bootstrapping algorithm was used to analyze indirect effects among the constructs. 


\subsection{Data Collection and Sampling}

This study mainly collects data via administering questionnaires, with all the personal information, remained confidential. The questionnaire method is selected because this approach can obtain primary information. The primary information is more direct and accurate and enables us to understand better the status of customers' intention to use QR code payment. Additionally, the data from the questionnaires is structured and it is convenient to be managed and analyzed.

The respondent's demographic characteristics are totally different, and the delivery of our questionnaires is random. By the online survey data collection system called Sojump, the questionnaire is available online and people can fill this by scanning QR codes by mobile phones or clicking the web link on a computer. Printed versions are also available for those people who prefer to fill in the hard copy survey. Some preliminary tests were essential before the actual data collection. Due to incomplete questionnaires, the final valid questionnaires were 422 , regardless of any other specific requirements. A high proportion of them would be university students or young adults in different parts of China.

All the questions are displayed in both English and Chinese to offer participants a better understanding. Besides, the questionnaire is divided into two parts. The first part is some general questions about the individual information (gender, age, education and the user experience). The second part is the measurement of different proposed constructs by a 7-point Likert scale $(1=$ totally disagree, $7=$ totally agree) in each question. Seven factors are evaluated (Attitude, Intention, Perceived Usefulness, Perceived Ease-of-Use, Perceived Security, Subjective Norms, and Perceived Benefits). All factors are measured by four different measurement items except Perceived Benefits, measured by three items. These statements are all adopted from previous research (i.e., Luarn and Lin, 2005; Parasuraman, Zeithaml, and Malhotra, 2005; Schierz, Schilke, and Wirtz, 2010). The measurement items of this questionnaire are illustrated in the Appendix.

\subsection{Data Analysis}

After data collection and cleaning, this paper will employ the Partial Least Squares Structural Equation Modeling (PLS-SEM) to conduct the data analysis. SmartPLS 3.2.8 will be used to operate the PLS-SEM technique.

Apart from PLS-SEM, another main approach to conduct SEM is the Covariance-based approach (CB-SEM). Compared to CB-SEM, PLS-SEM offers several advantages in some aspects. Firstly, PLSSEM is better at analyzing the data with a relatively limited sample size. Secondly, the distribution of the collected data is not necessarily normal. In reality, collecting the exact normally distributed data is difficult. Lastly, PLS-SEM is suitable for both exploratory and confirmatory research, while CB-SEM is only suitable to conduct confirmatory research. Exploratory research focuses on the reason why factors are related to each other and finding the potential relationship between elements. However, confirmatory research mainly aims to validate existing relationships but among different groups or in a different context.

By comparing PLS-SEM and CB-SEM, this paper selects PLS-SEM because of the following reasons. First of all, the size of the sample in this study is 437. The sample size is not large, and PLS-SEM offers rigor and convenience for the analysis of a small sample size. Additionally, some factors in the conceptual model proposed by this study are assumed to be related to each other, such as perceived usefulness, perceived ease-of-use. Therefore, this study is more suitable to conduct the exploratory factor analysis and PLS-SEM is an appropriate approach to carry out the analysis.

However, some limitations cannot be ignored by this method. The problems of multi-collinearity may appear if the data is not handled correctly. Another problem is that in this model, the relationship is single-pointed so that PLS-SEM cannot test the undirected correlation. Finally, this method lacks an overall evaluation of the model fit, which would cause some disadvantages in making judgments.

Scale reliability and validity will be examined. $R^{2}$ (goodness of fit), path coefficient size and the chosen significance level (5\%) will be demonstrated. Cronbach's Alpha is often regarded as the 


\begin{tabular}{|c|c|c|}
\hline $\begin{array}{l}\text { Demographic } \\
\text { Variables }\end{array}$ & $\mathrm{N}=422$ & Percentage \\
\hline Gender & $\begin{array}{c}\text { Male }=199 \\
\text { Female }=225\end{array}$ & $\begin{array}{c}\text { Male }=46.93 \% \\
\text { Female }=53.07 \%\end{array}$ \\
\hline Age & $\begin{array}{c}\text { Below } 20=81 \\
20-40=287 \\
40-60=56 \\
\text { ABOVE } 60=0\end{array}$ & $\begin{array}{c}\text { Below } 20=19.1 \% \\
20-40=67.69 \% \\
40-60=13.21 \% \\
\text { ABOVE } 60=0 \%\end{array}$ \\
\hline Education & $\begin{array}{c}\text { High school and below }=74 \\
\text { College }=92 \\
\text { Bachelor }=227 \\
\text { Master and above }=31\end{array}$ & $\begin{array}{c}\text { High school and below } \\
=17.45 \% \\
\text { College }=21.7 \% \\
\text { Bachelor }=53.54 \% \\
\text { Master and above }=7.13 \%\end{array}$ \\
\hline Main Purpose & $\begin{array}{l}\text { Payment }=387 \\
\text { Advertising }=14 \\
\text { Product trace }=5 \\
\text { Social media }=18\end{array}$ & $\begin{array}{c}\text { Payment }=91.27 \% \\
\text { Advertising }=3.3 \% \\
\text { Product trace }=1.18 \% \\
\text { Social media }=4.25 \%\end{array}$ \\
\hline User History & $\begin{array}{c}\text { Below } 1 \text { year }=69 \\
1-3 \text { years }=160 \\
\text { Above } 3 \text { years }=195\end{array}$ & $\begin{array}{c}\text { Below } 1 \text { year }=16.27 \% \\
1-3 \text { years }=37.64 \% \\
\text { Above } 3 \text { years }=45.99 \%\end{array}$ \\
\hline
\end{tabular}

judgment of scale's reliability. Robinson et al. (1991) confirmed an acceptable reliability coefficient for Cronbach's Alpha is around 0.7, so this study accepts constructs with the Cronbach's Alpha above 0.7 . Furthermore, convergent and discrimination validity are supposed to be scrutinized by the composite reliability and average variance extracted values, etc. All the results will be shown in the result part by the form of the table.

\section{RESULTS AND ANALYSIS}

This total number of questionnaires is 437 and 15 of them are excluded due to the incomplete responses. This study removes those invalid questionnaires, so the final sample size is 422 . The key tests and their meaning have been presented in Table 1 in the Appendix. Sample demographics are listed below in Table 2. The gender distribution of males and females is quite similar, at 199 and 225 respectively. For ages, over $67.69 \%$ of respondents are 20-40, ranking the first among all categories and no one is older than 60. Most participates have bachelor's degrees, followed by College diploma holders (92). Payment attracts almost 90\% QR Coder users as the most popular reason why they adopt the QR code and most of them have continuously used QR code over one year.

\subsection{Validity and Reliability Analysis}

Studies usually evaluate the within-scale consistency, which is generated from the responses to measure internal consistency. One of the widely acceptable coefficients used to analyze internal consistency is the Cronbach's Alpha. According to Robinson et al. (1991), this result was acceptable when the number was over 0.7 . In some other cases, 0.6 was also recognized for exploratory studies. The reliability analysis results of this study are illustrated in Table 3, and all the constructs have 


\begin{tabular}{|c|ccc|}
\hline & Cronbach's Alpha & $\begin{array}{c}\text { Composite } \\
\text { Reliability }\end{array}$ & $\begin{array}{c}\text { Average Variance } \\
\text { Extracted }\end{array}$ \\
\hline Attitude & 0.906 & 0.934 & 0.780 \\
\hline $\begin{array}{c}\text { Behavioral } \\
\text { Intention }\end{array}$ & 0.945 & 0.960 & 0.858 \\
$\begin{array}{c}\text { Perceived } \\
\text { Usefulness }\end{array}$ & 0.953 & 0.996 & 0.877 \\
$\begin{array}{c}\text { Perceived } \\
\text { Ease of Use }\end{array}$ & 0.950 & 0.964 & 0.870 \\
$\begin{array}{c}\text { Perceived } \\
\text { Benefits }\end{array}$ & 0.891 & 0.927 & 0.809 \\
\hline $\begin{array}{c}\text { Perceived } \\
\text { Security }\end{array}$ & 0.846 & 0.895 & 0.862 \\
\hline $\begin{array}{c}\text { Subjective } \\
\text { Norms }\end{array}$ & 0.921 & 0.944 & 0.809 \\
\hline
\end{tabular}

Cronbach's Alpha value over 0.7, indicating that variables in this model are reliable. The figures for the composite reliability of different constructs are also greater than 0.7 , which demonstrates satisfactory reliability. Concerning convergent validity, the cut-off value of 0.50 was provided by Hair et al. (2010) in terms of the average variance extracted (AVE). From Table 3, it is indicated that all the constructs in the study have the AVE value over 0.50. In addition to this, based on the results in Table 4 and the Fornell-Larcker Criterion, the model showed satisfactory discriminant validity.

\subsection{Structural Model and Hypotheses Testing}

This study proposes nine hypotheses based on both previous studies and additional arguments on the QR code payment. These measurements of each construct are adopted based on validated theories and existing studies. Partial Least Squares Structural Equation Modelling (PLS-SEM) technique is used to test all these hypotheses. In order to assess the significance level of path coefficients, subsamples are created with observations randomly drawn from the originating set of data and use 5000 as subsamples while using the bootstrapping algorithm. In Table 5, the result shows that, among nine hypotheses, seven of them are supported by at the 5\% significance level. The path coefficient also can be regarded as the principle to judge the hypothesis. Generally, this figure should be bigger than 0.1 significantly, with results shown in Table 4 and Table 5. Apart from two tests, all other tests pass the vigorous checks.

Hypothesis 1 is supported by data analysis ( $p$-value $=0.0000$, beta $=0.2824$ ). This means that the attitude is a validated direct motivator to the user's intention. Usually, from the psychological aspect, attitude consists of three elements: cognitive, affective and behavioral parts. The cognitive element refers to the psychological impression of the outer world, including related truth, knowledge and beliefs. For the active part, the core element in attitude decides people's positive and negative preference toward a certain issue or stuff. The last part is related to behavior intention, and it often represents people's tendency and action in preparation. In other words, people with a more positive 
Table 3. Discriminant Validity

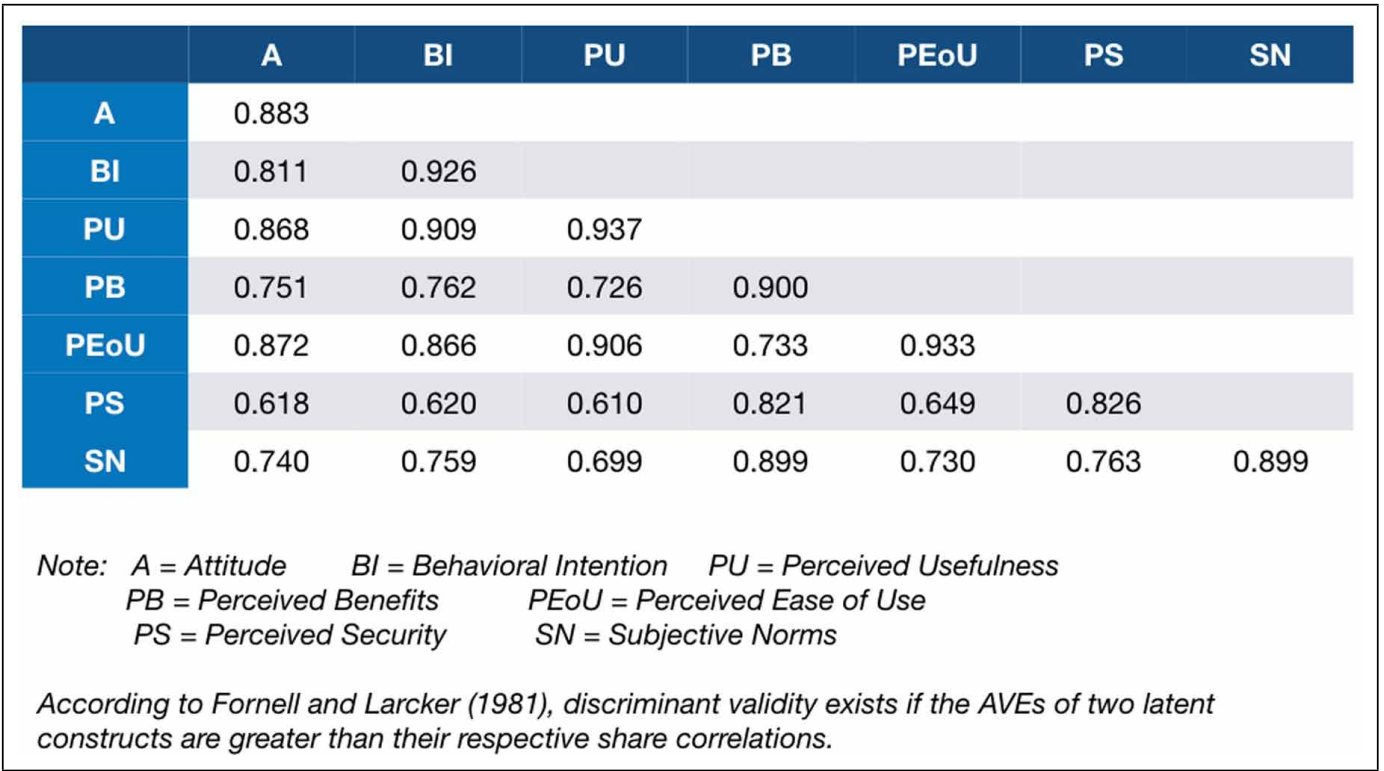

Table 4. Factor Loadings

\begin{tabular}{|c|c|c|c|c|c|c|c|}
\hline & A & BI & PU & PB & PEolU & PS & SN \\
\hline A1 & 0.878 & & & & & & \\
\hline A2 & 0.888 & & & & & & \\
\hline A3 & 0.868 & & & & & & \\
\hline A4 & 0.899 & & & & & & \\
\hline B1 & & 0.919 & & & & & \\
\hline B2 & & 0.921 & & & & & \\
\hline B3 & & 0.919 & & & & & \\
\hline B4 & & 0.945 & & & & & \\
\hline PU1 & & & 0.934 & & & & \\
\hline PU2 & & & 0.929 & & & & \\
\hline PU3 & & & 0.936 & & & & \\
\hline PU4 & & & 0.947 & & & & \\
\hline PB1 & & & & 0.860 & & & \\
\hline PB2 & & & & 0.909 & & & \\
\hline PB3 & & & & 0.929 & & & \\
\hline PE1 & & & & & 0.923 & & \\
\hline PE2 & & & & & 0.923 & & \\
\hline PE3 & & & & & 0.923 & & \\
\hline PE4 & & & & & 0.923 & & \\
\hline PS1 & & & & & & 0.846 & \\
\hline PS2 & & & & & & 0.846 & \\
\hline PS3 & & & & & & 0.846 & \\
\hline PS4 & & & & & & 0.846 & \\
\hline SN1 & & & & & & & 0.914 \\
\hline SN2 & & & & & & & 0.929 \\
\hline SN3 & & & & & & & 0.927 \\
\hline SN4 & & & & & & & 0.824 \\
\hline
\end{tabular}




\begin{tabular}{|c|rrrrrr|}
\hline & $\begin{array}{c}\text { Original } \\
\text { Sample }\end{array}$ & $\begin{array}{c}\text { Sample } \\
\text { Mean }\end{array}$ & $\begin{array}{c}\text { Standard } \\
\text { Deviation }\end{array}$ & T Statistics & P values \\
\hline A->BI & 0.2824 & 0.2816 & 0.0558 & 5.0600 & 0.0000 \\
\hline PU->A & 0.5859 & 0.5863 & 0.0688 & 8.5194 & 0.0000 \\
\hline PU->BI & 0.5475 & 0.5494 & 0.0642 & 8.5249 & 0.0000 \\
\hline PB->A & 0.1405 & 0.1399 & 0.0652 & 2.1564 & 0.0311 \\
\hline PEoU->A & 0.1042 & 0.1033 & 0.0754 & 1.3818 & 0.1671 \\
\hline PEoU->PU & 0.9057 & 0.9054 & 0.0159 & 57.1430 & 0.0000 \\
\hline PS->A & -0.0489 & -0.0477 & 0.0435 & 1.1245 & 0.2609 \\
\hline SN->A & 0.1657 & 0.1658 & 0.0630 & 2.6301 & 0.0086 \\
\hline SN->BO & 0.1671 & 0.1658 & 0.0358 & 4.6715 & 0.0000 \\
\hline
\end{tabular}

attitude towards this kind of payment method have a higher level of intention to use QR Code payment. This type of intention will contribute to real behavior, therefore, to adopt QR code payment.

Perceived usefulness is reported to be one of the significant indicators of attitude. There are some other antecedents proposed by this model that are assumed to have a positive contribution to attitude too, namely perceived ease-of-use, perceived security, perceived usefulness, perceived benefits and subjective norms. For perceived usefulness, the person who perceives $\mathrm{QR}$ code payment can improve his/her performance (better user experience) in the process of purchasing goods. They can hold favorable attitudes toward QR Code payment. More specifically, the user considers whether this new payment system can offer a quick transaction or whether the system can avoid cash exchanges into the decision of final use. Thus, the explanation is consistent with results in this study: the positive judgment will lead to a positive attitude.

Additionally, hypothesis 3 is supported by this study, which indicates that perceived usefulness also has a direct relationship with people's intention to adopt QR code payment. Same as perceived usefulness, perceived benefits affect people's attitudes positively, too, with a p-value less than 0.0311 . This means that people are sensitive to the promotions behind QR Code payment and the profits lead them to form a positive attitude about the adoption of QR Code payment. They choose this kind of way to pay because there are different types of rewards (i.e., vouchers, special discounts and membership and credits, which can be consumed as money). The subjective norm is also proved to be positively associated with attitude. This construct is derived from the Theory of Reasoned Action (TRA), which regards the social influence as one crucial driver to behavioral intention (Fishbein and Ajzen, 1975). People who receive social pressure (i.e., comments on personal user experience and suggestions on the usage of QR Code payment) tend to have a positive attitude to use the system. Nevertheless, this study assumes there is a relationship between subjective norm and attitude while there was no assumption made about this one in TRA Model. What proposed in the TRA was the links between 
subjective norm and intention directly. This relationship is also tested by the study, with the p-value less than 0.000. Subjective norms significantly motivate people to intend to pay by QR Code.

However, based on the data analysis result, Perceived ease-of-use and Perceived security are not supported to impose a significant impact on users' intentions at the 5\% significance level. Perceived ease-of-use mainly refers to the user's perception about whether the system is easy to use, and it does not impact users' intentions based on the result of this study. However, in many previous studies, this primary factor in UTAUT was validated significantly.

However, the entry-level for usage is simple. The user only needs a mobile phone with a builtin camera with an application provided by the QR code payment service providers. In addition, the process of QR code payment is to open the app, use the camera to scan the QR code, and use the payment code and the transaction ends. Some advanced software can automatically recognize the code and ensure the payers' information through fingerprint and facial expression.

Usually, the time needs to finish this process is less than 30 seconds. Third, a high proportion of respondents are young adults familiar with QR code payment and technology. However, the interesting point is that, according to the result of this study, perceived ease-of-use is associated with perceived usefulness. People think that these factors are positively related. For example, if the user finds that using the QR code is easy to use, he/she will have a higher level of perception towards the performance of this system. The situation is more complicated about whether there is a positive contribution form perceived security to attitude. This study does not support hypothesis 6 with a p-value of 0.2609 . Form the analysis to the original questionnaire. People hold a rather distinguished view towards whether the security matters when paying by QR code. For people aged below 20, they do not regard security as necessary as those who are above 40, and there is a noticeable disparity of the answers they choose. There may be outliers that are incredibly significant and then affect the hypothesis test. Young respondents grow up in the age of digitalization, and they recognize the convenience provided by QR Code payment more than the risk being involved. Therefore, young respondents are more open to new systems and willing to adapt. By contrast, for the middle-aged respondents, they hold a more conspicuous view of a newly available product or new service. Security is a pretty important element to evaluate the whole system.

Figure 3 illustrates the result based on the PLS-SEM analysis. This model explains $82.03 \%$ variances in Perceived Usefulness, $79.28 \%$ variances in attitude and $87.37 \%$ variances in Intention to Use. All these R-square values indicate that this model can operate satisfying prediction.

\subsection{Special Indirect Effect Analysis}

Besides the direct relationship, bootstrapping also provides an analysis of indirect effects and their coefficients with $\mathrm{T}$ statistics and p-value. The result is concluded in Table 6 above. Compared to the test of direct correlations, this unique analysis focuses on the corresponding total path to the determine construct, Behavioral Intention, of factors as perceived ease-of-use, perceived benefits and perceived benefits. Specifically, perceived ease-of-use affects users' intention through partial mediation by two paths. One is mediated by perceived usefulness and attitude to intention ( $\beta=0.1498, \mathrm{p}=0.0000$ ), and the other is mediated by perceived value to intention directly $(\beta=0.4959, \mathrm{p}=0.0000)$. This finding reveals that if the user finds that QR payment is simple, then the perception is related to both the user's positive attitude and a higher level of usefulness. Another path is from perceived benefits to attitude then to intention ( $\beta=0.0397, \mathrm{p}=0.0681$ ) and this indirect path is also significant with the $\mathrm{p}=$ value less than 0.005 . This explains that if the user perceives that he/she can get some benefits, such as different rewards (cash, credit, membership) behind the QR code payment, he/she has a more positive attitude towards QR code payment, leading to the higher motivation to adopt QR Code payment. Perceived ease-of-use and perceived security share the same mechanism to the intention by the mediator, attitude, but the consequences are not satisfied with a p-value 0.1899 and 0.2968 respectively because of some extreme distinguished personal view towards the importance of easeof-use and security among different people with various demographic information (i.e., age, education 


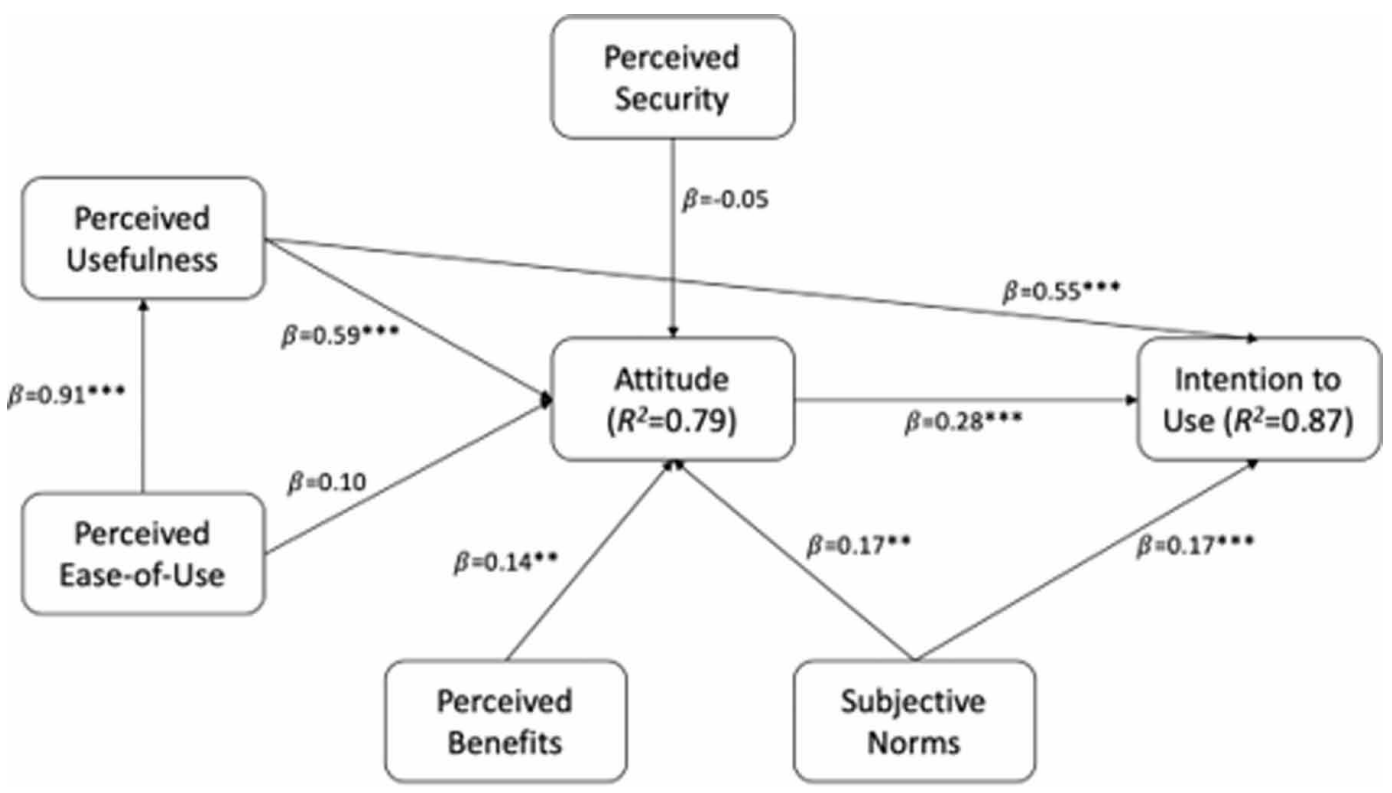

Table 6. Indirect Effects

\begin{tabular}{|c|c|c|c|c|c|}
\hline & $\begin{array}{l}\text { Original } \\
\text { Sample }\end{array}$ & $\begin{array}{l}\text { Sample } \\
\text { Mean }\end{array}$ & $\begin{array}{l}\text { Standard } \\
\text { Deviative }\end{array}$ & T statistics & $P$ value \\
\hline $\begin{array}{c}\text { PEOU->PU- } \\
>A\end{array}$ & 0.5306 & 0.5310 & 0.0644 & 8.2454 & 0.0000 \\
\hline $\mathrm{PU}->\mathrm{A}->\mathrm{BI}$ & 0.1654 & 0.1650 & 0.0379 & 4.3621 & 0.0000 \\
\hline $\begin{array}{c}\text { PEOU->PU- } \\
>\mathrm{A} \rightarrow>\mathrm{BI}\end{array}$ & 0.1498 & 0.1494 & 0.0344 & 4.3512 & 0.0000 \\
\hline $\mathrm{PB}->\mathrm{A} \rightarrow \mathrm{BI}$ & 0.0397 & 0.0402 & 0.0217 & 1.8247 & 0.0681 \\
\hline $\begin{array}{c}\text { PEoU->A- } \\
>\text { BI }\end{array}$ & 0.0294 & 0.0291 & 0.0224 & 1.3111 & 0.1899 \\
\hline $\mathrm{PS}->\mathrm{A}->\mathrm{BI}$ & -0.0138 & -0.0139 & 0.0132 & 1.0435 & 0.2968 \\
\hline$S N->A->B I$ & 0.0468 & 0.0465 & 0.0197 & 2.3757 & 0.0176 \\
\hline $\begin{array}{c}\text { PEOU }>\text { PU- } \\
>B \mathrm{BI}\end{array}$ & 0.4959 & 0.4976 & 0.0606 & 8.1785 & 0.0000 \\
\hline
\end{tabular}


gender). The multi-group analysis is a method to evaluate different path coefficients by the selected information category. Further analysis of why there is a significant disparity can be solved by the multi-group analysis, which can use the algorithm provided by SmartPLS.

\section{DISCUSSION AND CONCLUSION}

This paper studied users' motivations to choose the QR code as a payment tool by modifying the Unified Theory of Acceptance and Use of Technology. The new framework integrates 'attitude', 'perceived security', 'perceived benefits' as new constructs and excludes 'social influence'. Meanwhile, nine hypotheses were proposed. In this research, 422 questionnaires were collected from people in China with a different demographic background and are analyzed by SmartPLS using the Partial Least Squares Structural Equation Modeling method.

According to the result of this study, customers' intention of adopting QR Code payment was enhanced by the perceived usefulness, perceived benefits, and subjective norms. Specifically, for potential customers, they would intend to use QR code payments as follows. First, if they perceived that using the QR code would improve transaction efficiency of other applications. Second, their transaction cost would be reduced. Third, they could receive a discount by using it, or other people who are important to them are using it as well.

As a result, they needed to improve their service for the service providers, mainly in three aspects. First, the aim was to enlarge the range of use of QR Code payment. For example, the original QR Code payment was only for transactions such as purchasing goods from supermarkets or clothes in the store. In the future, it is possible to use QR Code payment to buy bonds, derivatives, and stocks in the financial market and use it to pay the bills of households. Second, the service providers in the large market share should promote some campaigns to offer benefits for customers. For instance, they can work with stores that provide QR code payments. If customers scan the QR code to make the payment, they can get a discount. These kinds of activities can attract more users.

Last but not least, service providers should investigate the users' experience regularly to solve the problem. If service providers can ensure users' rights and solve their problems timely and efficiently, the confidence of users on the QR code payment can be improved and enhanced. Then, there should be a higher possibility for the users to recommend QR Code payment to other people.

This paper offers several contributions to the literature. First of all, among the existing literature, lots of research has been conducted on mobile payment methods rather than QR code payment specifically. Additionally, most of the papers about QR code focused on other applications, rather than the mobile payment. Therefore, this paper contributes to the literature focused on $\mathrm{QR}$ code payment services. Secondly, the modified model is designed for the QR payment system specifically. Furthermore, with the modified model, service providers can identify the factors affecting customers' intention to use QR payment and take actions accordingly. With the improvement of usage rate and the support of IoT and Data analytics, merchants can adopt more attractive promotion strategies and develop more effective related-functions of QR code payment.

Limitations also exist in this study. A high proportion of respondents are university students or young adults in different parts of China. Although they are the main group of users, their opinions cannot represent the views of people of other ages or the general view in the QR Code area. Therefore, the future study can focus on samples with target demographic information or enlarge the sample size and use the multi-group analysis (MGA) to identify the gap between different user groups.

\section{ACKNOWLEDGMENT}

This research is supported by VC Research (VCR 0000037). 


\section{REFERENCES}

Ahmad, M. I. (2012). Incorporating Technology Acceptance into IT investment decisions: An exploratory study in Arab Republic of Egypt. Proc. of First International Conference on Computing and Informatics (ICCI'12).

Ajzen, I. (1985). From intentions to actions: a theory of planned behavior. In Action Control: from Cognition to Behavior. Springer-Verlag. doi:10.1007/978-3-642-69746-3_2

Akbar, F. (2013). What Affects Students' Acceptance and Use of Technology? Dietrich College Honors Theses.

Ashrafi, M., \& Ng, S. (2008). Enabling Privacy-preserving e-Payment Processing. Institute for Infocomm Research, 4947, 596-603.

Bayer, S., Gimpel, H., \& Rau, D. (2020). IoT-commerce - opportunities for customers through an affordance lens. Electronic Markets. .10.1007/s12525-020-00405-8

Campbell, D. T. (1963). Social attitudes and other acquired behavioral dispositions. Academic Press.

Cao, Q., \& Niu, X. (2019). Integrating context-awareness and UTAUT to explain Alipay user adoption. International Journal of Industrial Ergonomics, 69, 9-13. doi:10.1016/j.ergon.2018.09.004

Chen, H.-R., \& Huang, H.-L. (2010). User Acceptance of Mobile Knowledge Management Learning System: Design and Analysis. Journal of Educational Technology \& Society, 13(3), 70-77.

Chen, W., \& Wei, W. (2010). Structure equation modeling of relationship between corporate entrepreneurship and corporate performance. Journal of System Engineering, 025(002), 171-176.

Chiemeke, S. C., \& Evwiekpaefe, A. E. (2011, December). Review A conceptual Framework of a Modified Unified Theory of Acceptance and Use of Technology (UTAUT) Model with Nigerian Factors in E-commerce Adoption. Educational Research, 2(12), 1719-1726.

Denso Wave. (2018). QR code features. https://www.qrcode.com/en/index.html

Fishbein, M., \& Ajzen, I. (1975). Belief, Attitude, Intention and Behavior: A Introduction to Theory and Research. Academic Press.

Gao, , Yang, X., Guo, H., \& Jing, J. (2018). An Empirical Study on Users' Continuous Usage Intention of QR Code Mobile Payment Services in China. International Journal of E-Adoption, 10(1), 18-33. doi:10.4018/ IJEA.2018010102

Gefen, D., Karahanna, E., \& Straub, D. W. (2003). Trust and TAM in online shopping: An integrated model. Management Information Systems Quarterly, 27(1), 51-90. doi:10.2307/30036519

Gefen, D., \& Straub, D. W. (2000). The relative importance of perceived ease-of-use in IS adoption: A study of e-commerce adoption. Journal of the Association for Information Systems, 1(1), 8. doi:10.17705/1jais.00008

Hasbullah, N. A., Osman, A., Abdullah, S., Salahuddin, S. N., Ramlee, N. F., \& Soha, H. M. (2016). The relationship of attitude, subjective norm and website usability on consumer intention to purchase online: An evidence of Malaysian youth. Procedia Economics and Finance, 35, 493-502. doi:10.1016/S22125671(16)00061-7

Holden, R. J., \& Karsh, B. T. (2010). The technology acceptance model: Its past and its future in health care. Journal of Biomedical Informatics, 43(1), 159-172. doi:10.1016/j.jbi.2009.07.002 PMID:19615467

Jocevski, M., Ghezzi, A., \& Arvidsson, N. (2020). Exploring the growth challenge of mobile payment platforms: A business model perspective. Electronic Commerce Research and Applications, 40(November). .10.1016/j. elerap.2019.100908

Kalakota, R., \& Whinston, A. B. (1997). Electronic Commerce: A Manager's Guide. Addison Wesley.

Kim, C., Tao, W., Shin, N., \& Kim, K. S. (2010). An empirical study of customers' perceptions of security and trust in e-payment systems. Electronic Commerce Research and Applications, 9(1), 84-95. doi:10.1016/j. elerap.2009.04.014 
Kim, Y. G., \& Woo, E. (2016). Consumer acceptance of a quick response (QR) code for the food traceability system: Application of an extended technology acceptance model (TAM). Food Research International, 85, 266-272. doi:10.1016/j.foodres.2016.05.002 PMID:29544844

Lee, I., \& Lee, K. (2015). The Internet of Things (IoT): Applications, investments, and challenges for enterprises. Business Horizons., doi:10.1016/j.bushor.2015.03.008

Lee, J. H. (2015). A literature review on security for internet of things in Korea based on IoT S-P-N-D-Se ecosystem model. Journal of Security Engineering, 12(4), 397-414.

Lescevica, M., Ginters, E., \& Mazza, R. (2013). Unified Theory of Acceptance and Use of Technology (UTAUT) for Market Analysis of FP7 CHOReOS Products. Procedia Computer Science, 26, 51-68. doi:10.1016/j. procs.2013.12.007

Liébana-Cabanillas, F., Ramos de Luna, I., \& Montoro-Ríos, F. J. (2015). User behaviour in QR mobile payment system: The QR Payment Acceptance Model. Technology Analysis and Strategic Management, 27(9), 1031-1049. doi:10.1080/09537325.2015.1047757

Lim, S. H., Kim, D. J., Hur, Y., \& Park, K. (2018). An Empirical Study of the Impacts of Perceived Security and Knowledge on Continuous Intention to Use Mobile Fintech Payment Services. International Journal of Human-Computer Interaction. Advance online publication. doi:10.1080/10447318.2018.1507132

Luarn, P., \& Lin, H.-H. (2005). Toward an Understanding of the Behavioral Intention to Use Mobile Banking. Computers in Human Behavior, 21(6), 873-891. doi:10.1016/j.chb.2004.03.003

Mahon, D., Cowan, C., \& McCarthy, M. (2006). The role of attitudes, subjective norm, perceived control and habit in the consumption of ready meals and takeaways in Great Britain. Food Quality and Preference, 17(6), 474-481. doi:10.1016/j.foodqual.2005.06.001

Mazzei, D. (2020). A Blockchain Tokenizer for Industrial IOT trustless applications. Future Generation Computer Systems, 105, 432-445. doi:10.1016/j.future.2019.12.020

McDougall, G. H., \& Levesque, T. (2000). Customer satisfaction with services: Putting perceived value into the equation. Journal of Services Marketing, 14(5), 392-410. doi:10.1108/08876040010340937

Mohammad, I. A. (2014). Unified Theory of Acceptance and Use of Technology (UTAUT)- A Decade of Validation and Development. In proceedings of Fourth International Conference on ICT in our lives 2014 -Information Systems Supporting Decision Making. Information Systems and Computer Science Department, Faculty of Commerce, Alexandria University, Alexandria, Egypt.

Moon, J. W., \& Kim, Y. G. (2001). Extending the TAM for a World-Wide-Web context. Information \& Management, 38(4), 217-230. doi:10.1016/S0378-7206(00)00061-6

Nicoletti, B. (2017). The future of FinTech: Integrating finance and technology in financial services. Springer. doi:10.1007/978-3-319-51415-4

Ozturk, A. B., Bilgihan, A., Salehi-Esfahani, S., \& Hua, N. (2017). Understanding the mobile payment technology acceptance based on valence theory: A case of restaurant transactions. International Journal of Contemporary Hospitality Management, 29(8), 2027-2049. doi:10.1108/IJCHM-04-2016-0192

Parasuraman, A., Zeithaml, V. A., \& Malhotra, A. (2005). E-S-QUAL: A Multiple-Item Scale for Assessing Electronic Service Quality. Journal of Service Research, 7(3), 213-233. doi:10.1177/1094670504271156

Payment and Clearing Association of China. (2016). Available from: http://www.pcac.org.cn/eportal/ui?pageI $\mathrm{d}=598168 \&$ articleKey $=600007 \&$ columnId $=595052$

Payment and Clearing Association of China. (2017). Available from: http://www.pcac.org.cn/eportal/ui?pageI $\mathrm{d}=598168 \&$ articleKey $=599961 \&$ columnId $=595052$

Payment and Clearing Association of China. (2018). Available from: http://www.pcac.org.cn/eportal/ui?pageI $\mathrm{d}=598168 \&$ articleKey $=599943 \&$ columnId $=595052$

Rashed, J.M. (2001). Perception antecedents and their impact on user acceptance of information technology. Academic Press. 
Rauniar, R., Rawski, G., Yang, J., \& Johnson, B. (2014). Technology acceptance model (TAM) and social media usage: An empirical study on Facebook. Journal of Enterprise Information Management, 27(1), 6-30. doi:10.1108/JEIM-04-2012-0011

Robinson, J. P., Shaver, P. R., \& Wrightsman, L. S. (1991). Criteria for scale selections and evaluation. Academic Press. doi:10.1016/B978-0-12-590241-0.50005-8

Saadé, R., \& Bahli, B. (2005). The impact of cognitive absorption on perceived usefulness and perceived easeof-use in online learning: An extension of the technology acceptance model. Information \& Management, 42(2), 317-327. doi:10.1016/j.im.2003.12.013

Sang Ryu, J. (2013). Mobile Marketing Communications in the Retail Environment: A Comparison of Qr Code Users and Non-Users. International Journal of Mobile Marketing, 8(2), 19-29.

Sang Ryu, J., \& Murdock, K. (2013). Consumer acceptance of mobile marketing communications using the QR code. Journal of Direct, Data and Digital Marketing Practice, 15(2), 111-124. doi:10.1057/dddmp.2013.53

Schierz, P. G., Schilke, O., \& Wirtz, B. W. (2010). Understanding consumer acceptance of mobile payment services: An empirical analysis. Electronic Commerce Research and Applications, 9(3), 209-216. doi:10.1016/j. elerap.2009.07.005

Segars, A. H., \& Grover, V. (1993). Re-Examining Perceived Ease-of-use and Usefulness: A Confirmatory Factor Analysis. Management Information Systems Quarterly, 17(4), 517-525. doi:10.2307/249590

Shin, D. H. (2009). Towards an understanding of the consumer acceptance of mobile wallets. Computers in Human Behavior, 25(6), 1343-1354. doi:10.1016/j.chb.2009.06.001

Shin, D.-H., Jung, J., \& Chang, B.-H. (2012). The psychology behind QR codes: User experience perspective. Computers in Human Behavior, 28(4), 1417-1426. doi:10.1016/j.chb.2012.03.004

Singh, N., Sinha, N., \& Liébana-Cabanillas, F. J. (2020). Determining factors in the adoption and recommendation of mobile wallet services in India: Analysis of the effect of innovativeness, stress to use and social influence. International Journal of Information Management, 50(October), 191-205. .10.1016/j.ijinfomgt.2019.05.022

Smahi, A., Xia, Q., Xia, H., Sulemana, N., Fateh, A. A., Gao, J., Du, X., \& Guizani, M. (2020). A blockchainized privacy-preserving support vector machine classification on mobile crowd sensed data. Pervasive and Mobile Computing. Elsevier BV, 66, 101195. doi:10.1016/j.pmcj.2020.101195

Sorensen, E. (2018). Different types of mobile payments explained. Available at: https://www.mobiletransaction. org/different-types-of-mobile-payments/

Tasca, P., Aste, T., Pelizzon, L., \& Perony, N. (2016). Banking beyond banks and money. AG. Springer International Publishing. doi:10.1007/978-3-319-42448-4

Thakur, R. (2013). Customer adoption of mobile payment services by professionals across two cities in India: An empirical study using modified technology acceptance model. Business Perspectives and Research, 1(2), 17-30. doi:10.1177/2278533720130203

Venkatesh, V. (2000). Determinants of Perceived Ease-of-use: Integrating Control, Intrinsic Motivation, and Emotion into the Technology Acceptance Model. Information Systems Research, 11(4), 342-365. doi:10.1287/ isre.11.4.342.11872

Venkatesh, V., Morris, M., Davis, G., \& Davis, F. (2003). User Acceptance Of Information Technology: Toward A Unified View. Management Information Systems Quarterly, 27(3), 425-478. doi:10.2307/30036540

Xiong, C., Chang, V., Scuotto, V., Shi, Y., \& Paoloni, N. (2019). The social-psychological approach in understanding knowledge hiding within international R\&D teams: An inductive analysis. Journal of Business Research, (March). Advance online publication. doi:10.1016/j.jbusres.2019.04.009

Xu, B., Huang, D., \& Mi, B. (2020). Research on the application of mobile payment security system based on the Internet of Things. Concurrency and Computation, (March), 1-12. doi:10.1002/cpe.5779

Yang, K., \& Jolly, L. D. (2009). The effects of consumer perceived value and subjective norm on mobile data service adoption between American and Korean consumers. Journal of Retailing and Consumer Services, 16(6), 502-508. doi:10.1016/j.jretconser.2009.08.005 
Yang, S., Lu, Y., Gupta, S., Cao, Y., \& Zhang, R. (2012). Mobile payment services adoption across time: An empirical study of the effects of behavioral beliefs, social influences, and personal traits. Computers in Human Behavior, 28(1), 129-142. doi:10.1016/j.chb.2011.08.019

Yang, Y., Liu, Y., Li, H., \& Yu, B. (2015). Understanding perceived risks in mobile payment acceptance. Industrial Management \& Data Systems, 115(2), 253-269. doi:10.1108/IMDS-08-2014-0243 


\section{APPENDIX}

Table 7. Key indicators for statistical tests and their meanings

\begin{tabular}{|l|l|}
\hline Key indicator & Meanings \\
\hline R-squared value & $\begin{array}{l}\text { Describe the discrepancy between observed values and the values expected under the model in } \\
\text { question (Goodness of fit). }\end{array}$ \\
\hline Cronbach's Alpha & $\begin{array}{l}\text { The name used fir tau-equivalent reliability as an estimate of the reliability of a psychometric } \\
\text { test. }\end{array}$ \\
\hline $\begin{array}{l}\text { Average variance } \\
\text { extracts value }\end{array}$ & $\begin{array}{l}\text { A measure of the amount variance that is captured by a construct in relation to the amount of } \\
\text { variance due to the measurement error. }\end{array}$ \\
\hline P value & $\begin{array}{l}\text { For a given statistical model, the probability that, when the null hypothesis is true, the } \\
\text { statistical summary would be equal to, or more extreme than the actual observed results. }\end{array}$ \\
\hline
\end{tabular}

Table 8. Additional/optional tests for bootstrapping

\begin{tabular}{|c|c|c|c|c|c|c|c|}
\hline & A & BI & PU & PB & PEoU & PS & SN \\
\hline A & & & & & & & \\
\hline BI & 0.953 & & & & & & \\
\hline PU & 0.933 & 0.957 & & & & & \\
\hline PB & 0.757 & 0.751 & 0.703 & & & & \\
\hline PEoU & 0.891 & 0.913 & 0.951 & 0.715 & & & \\
\hline PS & 0.674 & 0.653 & 0.634 & 0.905 & 0.682 & & \\
\hline SN & 0.805 & 0.808 & 0.742 & 0.969 & 0.777 & 0.850 & \\
\hline
\end{tabular}


Victor Chang is a Professor of Data Science and IS at Teesside University, UK. He was a Senior Associate Professor, Xi'an Jiaotong-Liverpool University between June 2016 and Aug 2019. He was a Senior Lecturer at Leeds Beckett University, UK between Sep 2012 and May 2016. Within 4 years, he completed Ph.D. (CS, Southampton) and PGCert (HE, Fellow, Greenwich) while working for several projects. Before becoming an academic, he achieved $97 \%$ on average in 27 IT certifications. He won an IEEE Outstanding Service Award in 2015, best papers in 2012, 2015 \& 2018, 2016 European award: Best Project in Research, 2017 Outstanding Young Scientist and numerous awards since 2012. He is widely regarded as a leading expert on Big Data/Cloud/loT/security. He is a visiting scholar/PhD examiner at several universities, an Editor-in-Chief of IJOCI \& OJBD, former Editor of FGCS, Associate Editor of TII \& Info Fusion, founding chair of international workshops and founding Conference Chair of loTBDS, COMPLEXIS, FEMIB \& IIOTBDSC. He was involved in projects worth more than $£ 14$ million in Europe and Asia. He published 3 books and edited 2 books. He gave 25 keynotes internationally as a top researcher.

Waner Chen was Prof Chang's final year student at Xian Jiaotong-Liverpool University between 2018 and 2019. She is now an MSc student at the Business School, Imperial College, UK.

Miss Qianwen Xu is graduated with MSc in Business Analytics with Distinctions from International Business School Suzhou, Xi'an Jiaotong-Liverpool University (XJTLU), Suzhou, China and University of Liverpool, UK. She has worked under Prof Chang's supervision and also as a part-time research assistant. She is a hardworking, dedicated and resourceful student who can make things happen. She will study PhD under Prof. Chang's supervision.

Chang Xiong is a Lecturer at HeXie Management Research Centre, Xi'an Jiaotong-Liverpool University, China. He has a PhD degree in Management from The University of Liverpool. Prior to his PhD study, he has completed a Master's degree in Economics from the University of Manchester in 2015. He is trained to conduct both qualitative and quantitative research within a range of management/marketing topics. Previously he has also worked as a Research Assistant at SKEMA Business School Suzhou campus, where he was involved in a variety of collaborative research projects with Tongji University and Shanghai University of Finance and Economics. 